\title{
A Didactic Pedagogical Approach toward Sustainable Architectural Education through Robotic Tectonics
}

\author{
Xinyu Shi ${ }^{1,2} \mathbb{0}$, Xue Fang ${ }^{1,2, *}$, Zhoufan Chen ${ }^{3}$, Tyson Keen Phillips ${ }^{4} \mathbb{D}$ and Hiroatsu Fukuda ${ }^{2, *}$ \\ 1 iSMART, Qingdao University of Technology, Qingdao 266061, China; sxy@qut.edu.cn \\ 2 Faculty of Environmental Engineering, The University of Kitakyushu, Fukuoka 802-8577, Japan \\ 3 Perkins and Will, Los Angeles, CA 90017, USA; zhoufan.chen@ucla.edu \\ 4 Robotics Lab, IDEAS Campus, Architecture and Urban Design, UCLA, Los Angeles, CA 90095, USA; \\ tyson.phillips@aud.ucla.edu \\ * Correspondence: fangxue@qut.edu.cn (X.F.); fukuda@kitakyu-u.ac.jp (H.F.); \\ Tel.: +86-(0)532-8507-1127 (X.F.); +81-(0)93-695-3242 (H.F.)
}

Received: 12 February 2020; Accepted: 25 February 2020; Published: 27 February 2020

\begin{abstract}
Robotic tectonics have been integrated into the architectural profession through automated construction for more than a decade, advancing sustainability initiatives in the industry and increasing the quality of building construction. Over the years, avant-garde architects have explored the feasibility of this new design paradigm through the integration of newly-developed digital design software into automated construction. This robotic digital workflow continues to push designers to re-think the complete architecture process (from design conception to physical construction) and guides the building industry towards more precise, efficient, and sustainable development. However, in the current environment of architectural education, professional courses can be fragmented, thematic, and overly academic. Such content is not inherently compatible with the latest technological developments. The lack of understanding and application of digital technological can subsequently lead to the lack of sustainable development in architectural education. In this paper, we aim to introduce a new didactic pedagogical approach that is reliant on the principles of robotic tectonics and is defined through linear development in four distinct, developmental stages (based on information gleaned from four "Robotic Tectonics" workshops and various other rich teaching practices). This pedagogical framework provides interdisciplinary knowledge to architecture students and enables them to use advanced digital tools such as robots for automated construction, laying the groundwork for the discovery of new and complex building processes that will redefine architecture in the near future.
\end{abstract}

Keywords: sustainability; robotic tectonics; architectural education; automated construction; workshops

\section{Introduction}

In modern times, the pursuit of sustainability requires systematic and balanced development between environmental, sociocultural, and economic efforts [1-4]. Sustainability, productivity, and improved economic efficiency can be more readily achieved with the help of sophisticated technology [5-8]. The architecture, engineering, and construction (AEC) industry is one of the key components of the sustainability movement $[9,10]$, and is currently faced with a myriad of challenges such as rapid changes in digital technology and shifting societal values [11]. Likely, automation will be the catalyst that will accelerate the building industry from traditional, inefficient, and labor-intensive practices toward the opportunity to build more efficiently, accurately, and creatively [12,13]. Along with the emergence of digitalization, virtual production, and computational analysis in the past 50 years, programmable robotics has greatly expanded the field of automation to make it smarter, more 
flexible, and more versatile [14,15]. These qualities suggest that it could similarly cater to the building industry in the current digital age [16,17]. It is not farfetched to regard computer programming and architectural construction as reliant upon each other and to see their reciprocity as fundamental to architectural practice $[18,19]$. In such a manner, the industrial robot may become both a symbol of, and a primary tool for, a profound reformation of the discipline [20]. Thus, with the interdisciplinary requirements and technical difficulty of robotic tectonics, how can we integrate it into architectural education in a simple and understandable way that can allow students to master the necessary skillset while addressing the critical challenge of sustainable development in architecture? As a response to this challenge, we are pushing to establish a novel workflow that can act as a model for a digitally-focused pedagogy and define it within a sustainable framework that combines advanced robotic technology and architectural tectonics. We intend to focus on construction techniques driven by robotics in order to significantly improve material, structural, energetic, and procedural efficiency, all while promoting the aesthetic innovation emblematic of an architectural education. In this linear model, we aim to test the integration of a variety of interdisciplinary techniques in the early design stages that we believe will aid in the advancement of sustainable development [21-24].

The introduction of automated construction can be traced back to the manufacturing of industrialized building components and the prefabrication of modular homes in Japan in the 1970s [25]. Subsequently, the first full-scale application of an automated building construction project was completed in 1991 in Japan [26]. For years, robots have been employed exclusively by industrial manufacturers, but recently, avant-garde architects have begun to explore using this technology as a tool for architectural tectonics that could be introduced into professional practice. In 2006, Fabio Gramazio and Matthias Kohler built the first robotically-assembled wall in Zurich, developing a workflow that challenged the current limitations of computational digital fabrication in design and construction [27]. Studies strongly suggest that the conventional construction methodology has reached its limits in sustainable development [28]. We believe the relevance of robotic tectonics is growing (advancing mostly in unstructured environments such as research labs and universities), and it may have the potential to serve as the catalyst for the automation of construction across the diverse architectural field $[29,30]$.

As a response to the current demands of industry and architectural logic, the way buildings are designed, built, and operated needs to change [31]. The relationship between architects and robotic technology seems to raise challenges that have triggered a cultural shift in architectural pedagogy to encourage adaption to the building industry's demands [32]. Many institutes and universities have explored advanced robotic automation practices and organized similar research efforts over the past few decades [33]. In fact, the top twenty architectural universities in the world have all offered courses or workshops related to robot-based architectural design, encouraging a wide range and highly advanced robotic skills such as digital design, programming, and construction of structural assemblies [34]. However, only $10 \%$ of architectural universities offer relevant courses in China, and half of them do not provide the necessary facilities [35]. Without proper facilities, although the teaching framework and content of each course are valuable, practical application and project completion cannot yet be explored at a satisfactory level [36].

Therefore, we have dedicated ourselves to the development of this new pedagogical approach and tested its administration through the completion of four workshops (once a year since 2016) in an attempt to explore how robotic tectonics improves architectural education for sustainability [37]. These workshops represent the complete workflow of robotic tectonics, which can be summarized as a compendium of four distinct stages ranging from digital design to fabrication. Each stage has its unique contributions to sustainability, while the overall system operates as a paradigm shift in architectural education to maximize its impact on the AEC industry. This workflow proves that using robotic tectonics in education can contribute to the underpinning of sustainable development in architectural practice and nurture innovation in future architects who are going to be closely tied to the building industry for decades to come. 


\section{A Pedagogical Framework for Robotic Tectonics}

Education is of utmost importance for the future of sustainable development, especially in the field of architecture [38]. It is a key factor in the reorientation of the construction industry toward a system of more responsible buildings and cities [39]. The daunting task is finding a way to provide the necessary knowledge to future professionals, which will empower them to deal with impending environmental issues through the integration of novel design methodologies and technology [40]. In order to better address sustainability through development of creativity and technical skills, it is necessary to reconsider the current implementation of sustainable design methods at the educational level [41].

Since its induction in 2016, DAMlab (digital architecture and manufacturing laboratory) has established an experimental teaching platform exploring a myriad of digital tools including three KUKA robots (KR120R2700, KR60R2100, KR9R1100) and various CNC machines. Since then, we have hosted several workshops focused on the topic of robotic tectonics. From these last three years of teaching practices, a prominent didactic pedagogical approach has emerged. This new pedagogy is a fully comprehensive robotic tectonic workflow, but it is more easily understood through its four stages-parametric design, cross-data simulation, robotic application, and robotic construction. Within the confines of these individual stages, students can easily break down this overly complex and technically difficult workflow into successive phased steps, each of which contributes to the learning objectives of this new pedagogy (Figure 1).

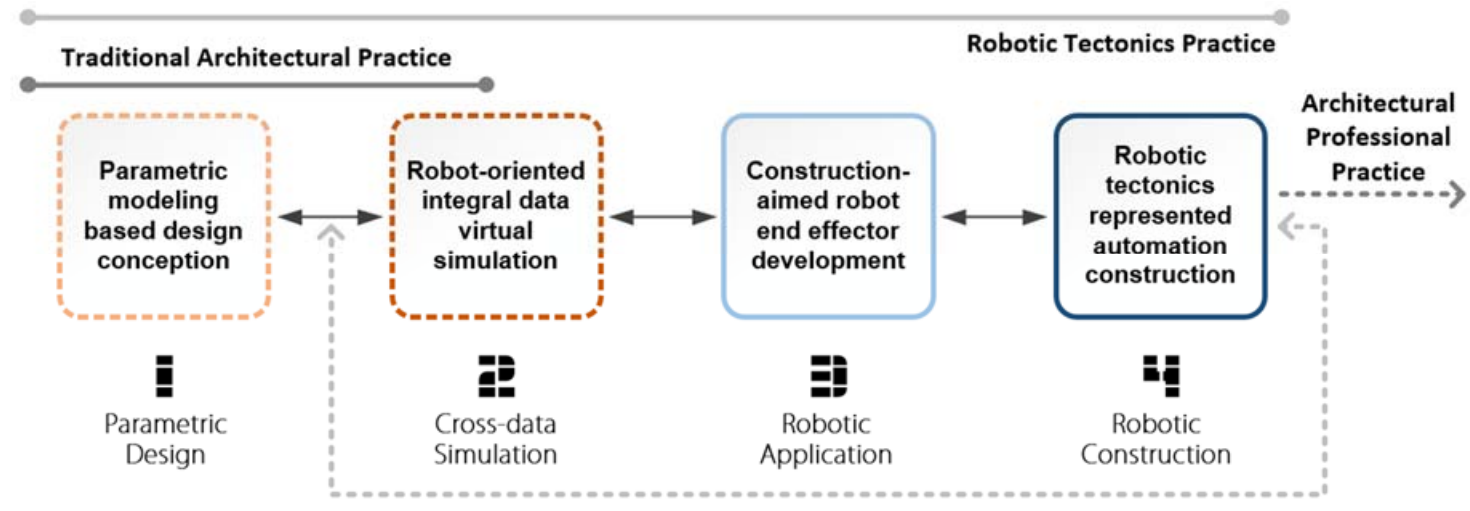

Figure 1. Diagram of the robotic tectonics workflow.

This framework explores the entirety of the typical design and construction cycle, providing the necessary technical skills required to make automated construction into a reality. It expresses a global initiative for students to understand and apply contemporary technology to critical thinking in order to pursue design innovations towards a more sustainable future. Leaders in automated construction practices must be proficient not only in traditional computational and technical skills, but also in a new form of digital materialization, which includes a critical understanding of constantly changing manufacturing processes.

\subsection{Parametric Design: A Parametric Model-Based Design Conception}

Parametric modeling has played a significant role in architectural design in the last few decades [42]. One of the most important features of parametric modeling is that its attributes can be relationally linked to one another in order to easily and actively change their features. This allows the designer to define entire classes of forms by simply changing relevant key parameters (as opposed to changing each individual instance). Before the advent of parametric modelling, editing complex forms directly in the 3D modeling software was mundane work. As a simple example, modification of any geometry required the designer to change its length, breadth, and height independently. However, with parametric modeling, the designer needs only to alter one of such parameters, as the others may be 
relationally bound to it. If one is changed, the other two parameters adjust automatically. Parametric models such as this focus less on the forms and more on the logical steps used to create the forms, thus benefiting the user in time-sensitive, dynamic design scenarios.

Grasshopper (a modeling plugin for the 3D modeling software Rhinoceros) has been the primary parametric software of choice for architects and students of architecture. Its unique visual programming interface allows designers to more easily understand parametric logic and ultimately save time in design generation and manipulation. The interface between the design "script" and the corresponding digital 3D models allows the designer to focus on the logic that can directly define building forms, as opposed to the forms exclusively.

Students subscribing to the robotic tectonic pedagogy are first introduced to parametric software such as this as a tool to explore the logic of geometrical systems so that they can begin to consider its use for generating design concepts. The impetus for exploring parametric logic in the first stage is to have students gain the ability to easily capture design intent and define families of building elements, thus anticipating the forthcoming industry-driven manufacturing processes in which production and fabrication methods have a massive impact on the built world.

\subsection{Cross-Data Simulation: A Robot-Oriented Integral Data Virtual Simulation}

Once these relationships are programmed to conceptualize new building and construction logic, the same virtual model can then be used to create simulations for fabrication or assembly. This single virtual model represents a combination of various logic-based databases such as geometry, spatial location, form generation, construction sequence, simulation data, operation constraints, etc. The parametric model establishes links between all of this data, resulting in a comprehensive simulation mechanism in which the revealed robotic operations will most definitely have an impact on the overall design.

Thanks to the advanced robotic simulation and control software KUKA|prc (which is embedded in Grasshopper), the simulation of the robotic construction process has become more accessible to designers. It provides a virtual, visual simulation in a safe environment for students or architects to analyze every detailed step of the construction process previous to its implementation. Simulation is set as the second stage of the overall pedagogy in order to help students gain robotic operational skills and to trigger critical thinking about the impact of these operations so that they can later optimize the parametric design concepts generated in the previous stage.

\subsection{Robotic Application: Construction-Aimed Robot End Effector Development}

Programming the robots' movements in virtual simulation software is already quite a complicated process, but it is merely a representation of the construction workflow that will need to be utilized in order to bring these designs into reality. Generally speaking, industrial robots can only respond to positional commands, and they have no awareness of what is going on in their environment. This could lead to unforeseen motion that can damage the environment, the work, or even the people in proximity to the robot. Therefore, any form of automation in the realm of construction needs a carefully programmed, simulated, and detailed model of its operating environment, especially when it comes to the design and integration of construction-oriented end effectors into the system.

The end effector (sometimes called the end tool) is arguably the most important component of the industrial robotic arm. It helps to realize the construction or fabrication sequence, and it is the only part of the robot specifically designed to interact with its physical environment. Its weight, shape, function, and precision are all critical to the construction process. Therefore, the objective of this stage is to guide students to understand the importance of interdisciplinary cooperation between engineering and design, and to introduce them to construction-oriented robotic end tools. These tools, as instrumental aspects of robotic fabrication, need to be customized and integrated by those under the robotic tectonic pedagogy so they (the students) can provide maximum flexibility for robots as automation tools, thus continuing to enhance the efficiency of the overall system. 


\subsection{Robotic Construction: Robotic Tectonics Represented through Automated Construction}

The final stage of this workflow is robotic construction, where both successes and design defects from the construction process can turn into priceless experiences that then feed back to the early stage of design conception and simulation [43]. This holistic look at design reveals that the entire robotic tectonics process is one of dynamic adjustment and adaptation, making it extremely beneficial to explore at the educational level. This stage aims to provide a comprehensive testing environment for students to utilize all of the previously mentioned techniques and focus them on their final construction goals. The efficiency of the robot and the accuracy of the construction method depend on iteratively fine-tuning the relationship between the program, the robot, the tool, and the material. Robotic construction brings all of these components into a single realized outcome to get students to begin to think critically about improvements to sustainability in the architectural future.

Solving all of the physical considerations involved in the robot workflow is a priceless exercise that produces cascading effects throughout the education process. Once these components are fully designed, they must be modeled and programmed into a digital simulation. It is through this exercise that students gain an understanding of the process of dynamic adjustment and adaptation, which helps to see how computational information and robotics relate to each other and what they can achieve when used in tandem.

\section{Robotic Tectonics Teaching Practices: Toward a Sustainable Architectural Education}

To test DAMLab's experimental platform, we applied this pedagogical approach to several experimental teaching practices, including four international workshops and dozens of classes and lectures. The four workshops are outlined below, each representing a successful application of the new pedagogy. Not only are each of the workshops a complete experiment exploring the entire robotic tectonic workflow, but each one also imposes a more targeted emphasis on one of the four stages in order to explore that stage's role in architectural education in detail. In addition, the workshops each take on a different material exploration to test diverse application of the didactic platform. The workshops are as follows: Robotic Clay Printing (exploring parametric design in-depth), Robotic Foam Cutting (exploring cross-data simulation in-depth), Robotic 3D Spatial Printing (exploring robotic application in-depth), and Robotic Wood Assembly (exploring robotic construction in-depth).

\subsection{Robotic Clay Printing}

As of late, clay has been utilized more frequently among architects and fabricators thanks to the success of 3D printing in industrial production. Clay has good sound absorption, water absorption, opacity, air permeability, and resistance to corrosion, all of which make it suitable for a variety of applications in the AEC industry. On top of this, its fluidity, plasticity, firmness, and cured strength allow it to meet the basic structural and physical requirements of 3D printed materials. The precise and programmable parameters of a standard clay extruder allow the material to be explored in a dynamic shore range, from soft (flowing) to hard (extruding). Control over these complex attributes inspires further exploration into surface texture and formal aesthetic of the final clay print [44]. In addition to the material's aesthetic qualities, the digital fabrication workflow allows us to obtain a quantitative analysis of the benefits of different textures and forms achievable.

Due to the potential of clay printing at an architectural scale, it was incorporated into the DAMlab workshop in April 2019, where it was explored under the constraints of parametrically generated façade panels. The workshop was used to study clay's physical properties, its application potential, the optimization of its geometry, and the optimization of its printing process. At the outcome of the workshop, a parametric facade panel prototype was fabricated to highlight the advances in the new clay printing system (Figures 1 and 2). 


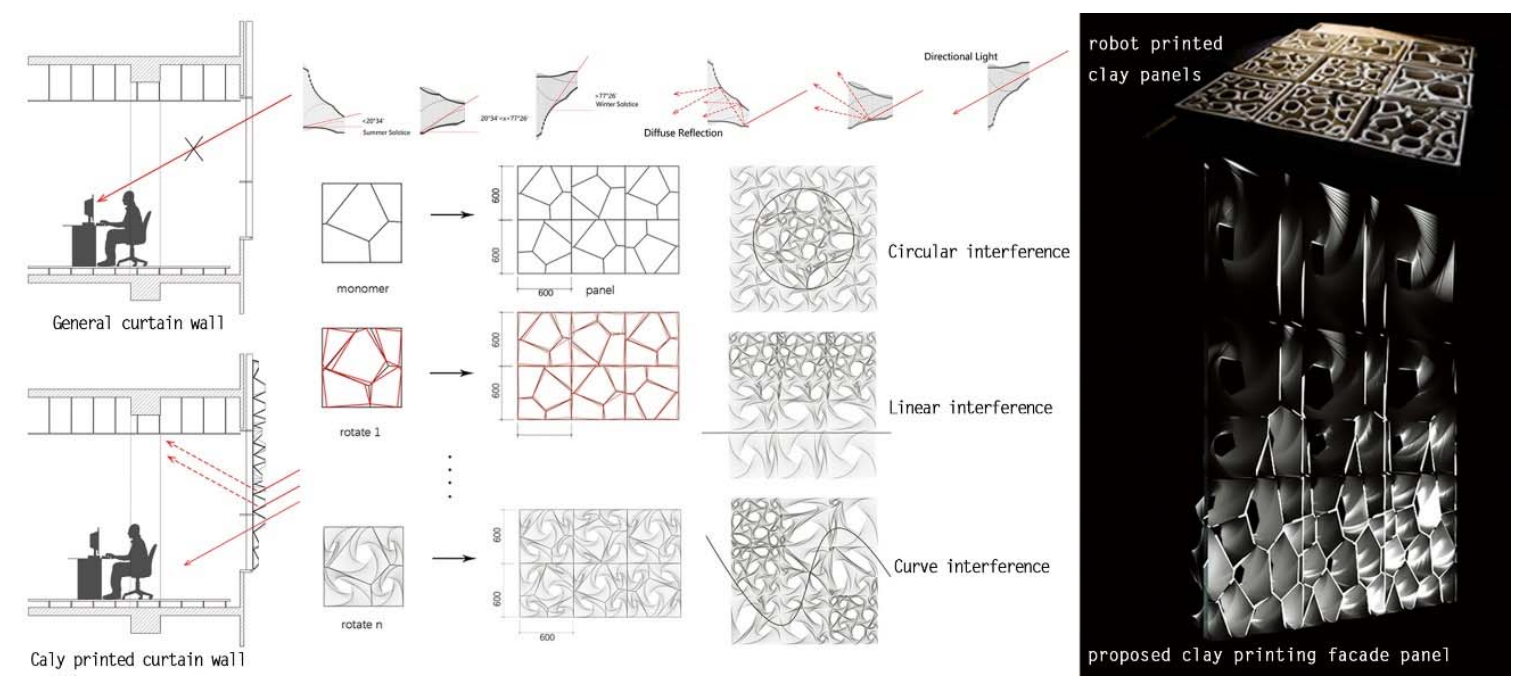

Figure 2. The parametric modeling process for the clay printing panels.

Clay printing and plastic FDM (fused deposition modeling) 3D printing share the same characteristics, since both offer construction through layer deposition. However, rather than focusing on printing accuracy and the resolution of the final product, robotic deposition can explore the potential functionality embedded with the layer structure [45]. The surface texture produced by both the laminated printing method and the matte texture of the clay provides a large amount of surface area with diffuse reflection on the finished product. This unexpected attribute implies this fabrication method may be best suited for an architectural application, which requires high levels of light control. It would likely perform best as a façade panel of a building, which requires more soft light and reduced glare in the interior environment. As the aperture size and directionality of the nodes can be parametrically optimized over the entire facade, the sun's intensity inside the building over the course of the day can be abated to reduce the amount of direct sunlight that reaches the interior. Thus, the first stage of the pedagogy (parametric modelling) plays a significant role in this particular workshop.

The basic module used for the facade panel is a $600 \mathrm{~mm} \times 600 \mathrm{~mm}$ square, which is then subdivided into multiple Voronoi polygons. Each Voronoi polygon forms the basic unit of a single facade panel and can be unique to its neighboring panels through transformational actions such as rotating, scaling, and translating. Interlinked relationships between the neighboring panels were established in Grasshopper, implementing precise control over the normal angle the Voronoi polygons, ultimately controlling the light transmittance of the entire facade panel (Figure 2). An environment analysis was then simulated with the Ladybug plugin in order to quickly iterate through design options based on the desired direct and indirect interior light values.

Though parametric iteration is a critical part of this design process, fabrication must also be considered in the overall design development. Therefore, the other three stages of the didactic pedagogy must be considered. Since the panel is composed of multiple Voronoi polygonal monomers, it is necessary to print multiple pieces at the same time and to optimize the printing path between adjacent monomers in order to ensure the strength of their connection. This makes the fabrication process of the panel different from the continuous extrusion employed in standard clay printing. Likewise, the form of the panel has to be optimized by the physical constraints of its physical construction. Prior to the final printing, the maximum height of the clay print, the maximum dislocation distance between the upper and lower layers, and the optimal thickness of each layer were tested and digitized so that the optimal form of each panel could be adjusted according to the data. Thus, as all aspects of design and fabrication fall back on parameterization for improving the efficiency of the overall system, it becomes critical as an introduction to the sustainable pedagogy. 


\subsection{Robotic Foam Cutting}

The hot-wire foam cutting project aims to build a single continuously curved periodic surface, which can then be assembled into a greater complex form with blurred boundaries-a space that could be inhabited and used for meditation and relaxation. By converting the digitally generated form into the robot tool path for the hot-wire cutting tool, the physical robot can precisely cut the EPS (expanded polystyrene) foam into a continuous three-dimensional surface, which can act as a building block for a single aggregated surface that can be infinitely extended. As a fundamental part of this project, the link between the form generating script and the tool-path generating script was prioritized, which allowed the resulting virtual simulation to aid in the optimization the fabrication process (Figure 3). Thus, this project was selected to primarily represent the second stage of cross-simulation data and how it is necessary to the overall pedagogy.
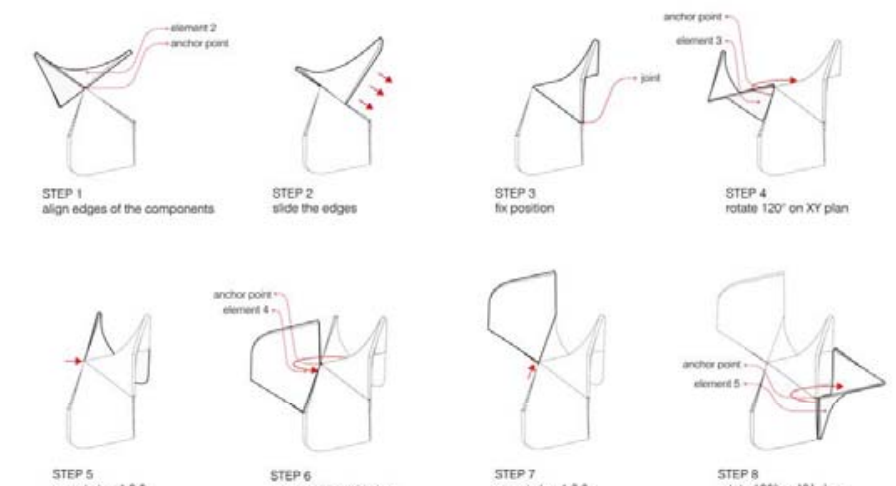

STEpes 5

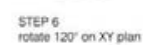

STEP 7
roppoar stop 123
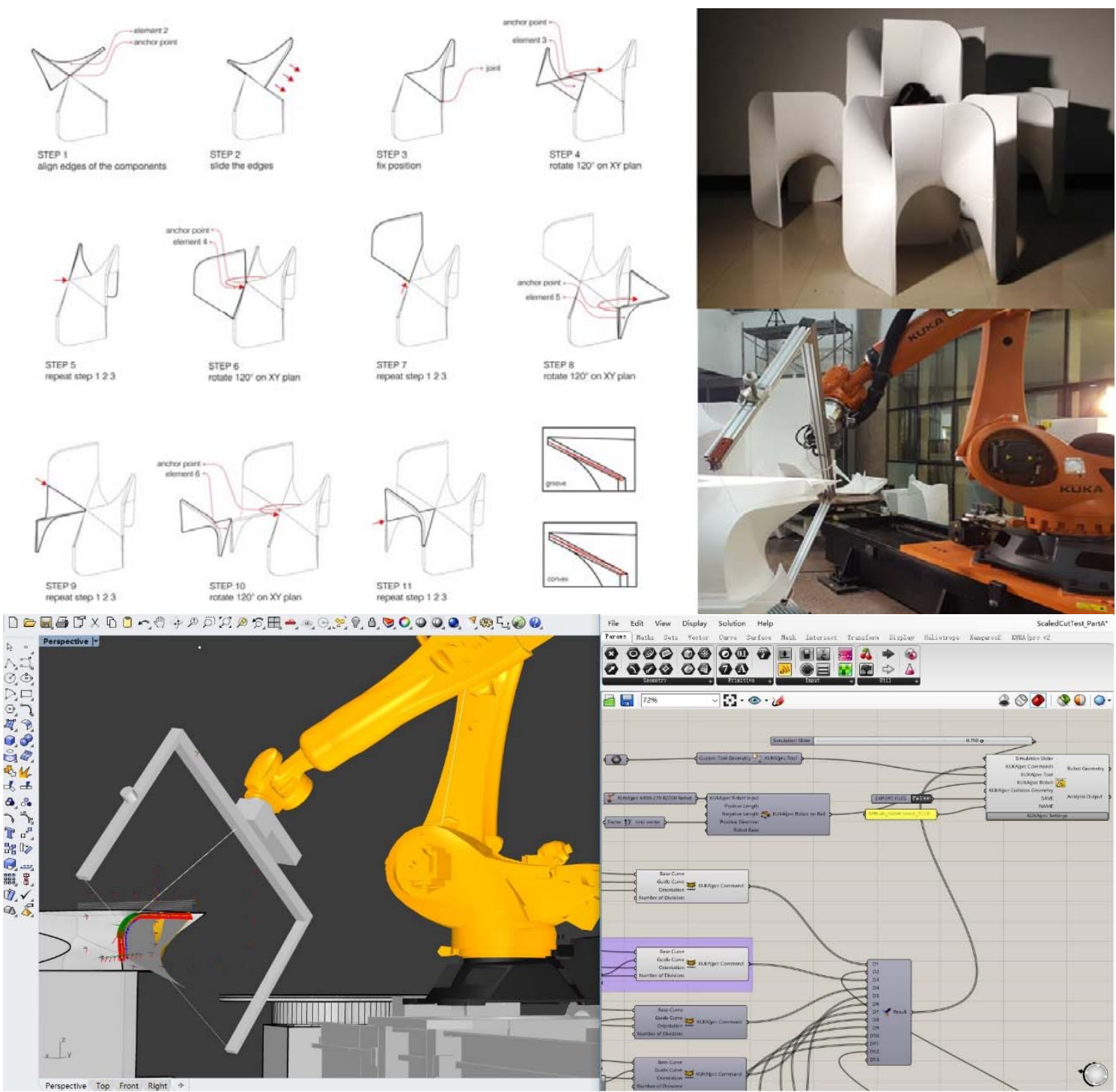

Figure 3. Simulation for the robotic tool path corresponding to desired forms.

To systematically link the form generation to robotic motion, the periodic surface component to be cut was abstracted into a single, continuous curve. This allowed the surface to be the driver for the motion path for the hot wire end-tool. With each new part as a discreet element in the whole aggregation, the tool-path of each piece had to be continuously adjusted to reflect any changes made to the final form. This link allowed the team to visualize the fabrication process and optimize the 
rotational movement of each axis prior to the final cutting, reducing both production time and potential for fabrication error. Needless to say, the other stages of robotic tectonics also have an effect on the simulation data. The shape and angle of the hot-wire tool, as well as the physical constraints of the foam material, heavily influence the constraints of fabrication with regards to the robot's motion paths. Due to the complexities of this foam-cutting process, one can see that simulation is integral to the overall platform as both a constraint and a design opportunity.

\subsection{Robotic 3D Spatial Printing}

Polylactide (PLA) must be heated to a very specific temperature before it converts to a more viscous form [46]. For proper spatial printing, when the molten material meets the cold air at the extrusion nozzle, the material temperature must then decrease rapidly. If done properly, the molten plastic quickly solidifies in mid-air. This unique feature achieves the formal qualities of 3D printing without relying on the traditional layering technique. The robot arm, unlike other deposition tools, can accurately navigate to the position of each node in the structure and quickly construct a self-supporting unit, eventually resulting in the designed form (Figure 4).
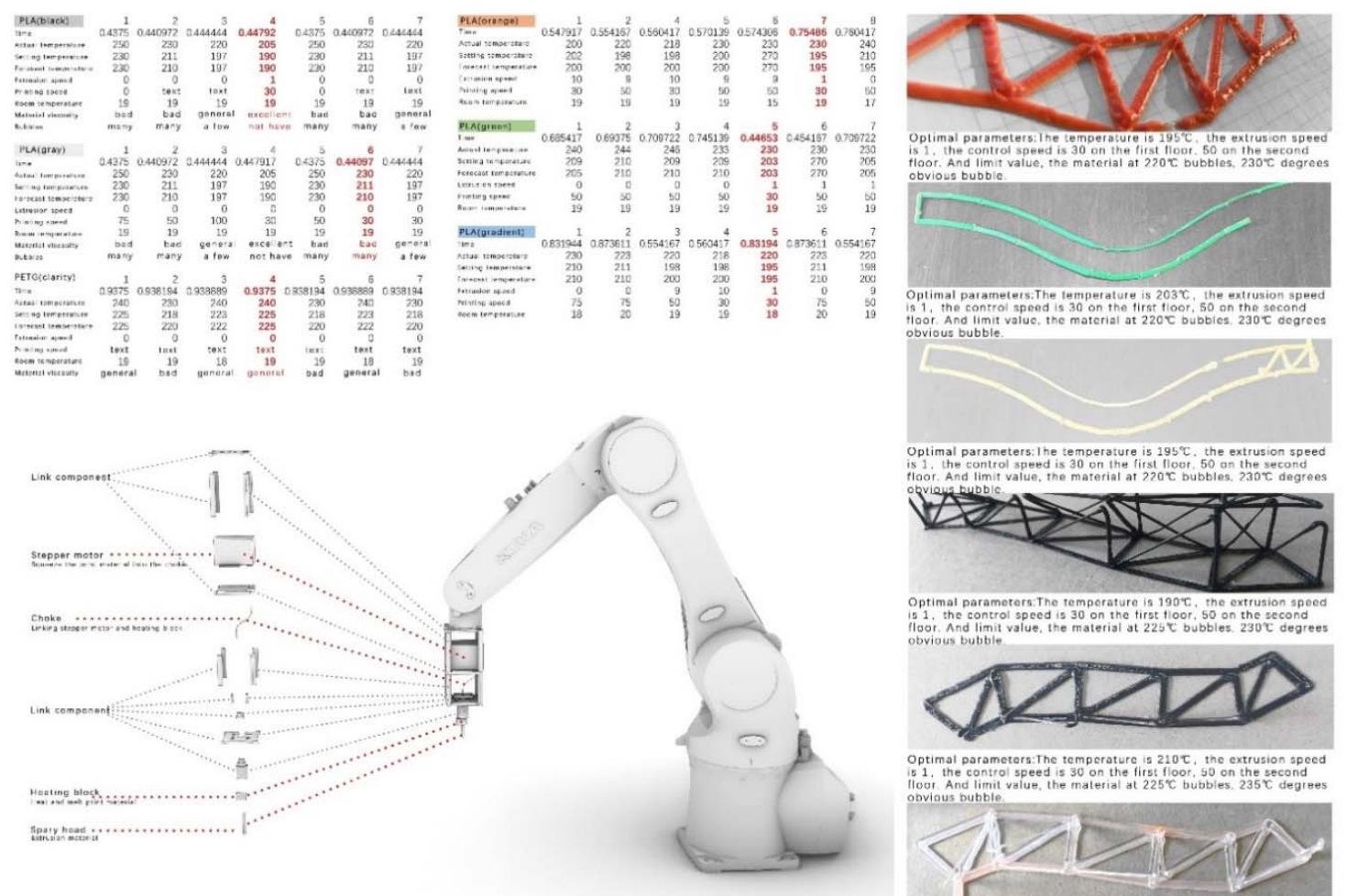

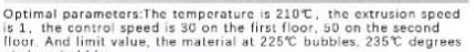

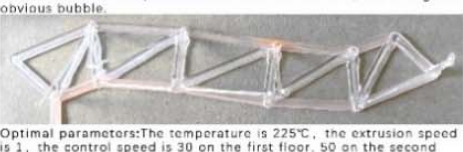

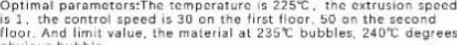

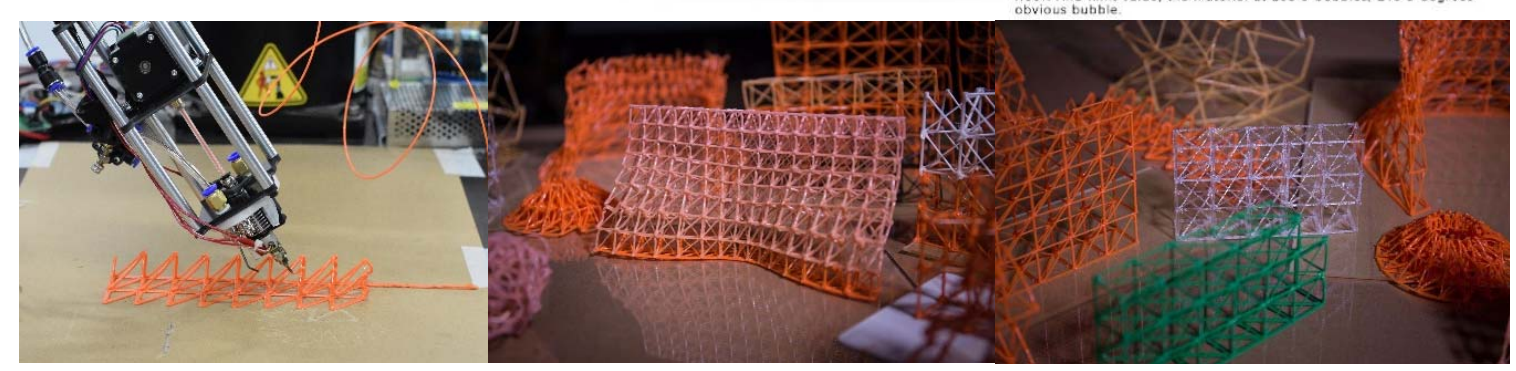

Figure 4. Custom robotic printing tool designed for different materials.

Compared with the traditional fused deposition 3D printing (FDM), spatial 3D printing has several advantages $[47,48]$. Firstly, while ensuring the strength of the structure, spatial 3D printing can build 
components of similar volume in less time and with less material. With the robot arm, the position of each printed node is more accurate, which greatly improves the aesthetics and structural stability of the components. Secondly, the spatial printing process is less limited by the need for support material, so the standard restrictions on the final form are greatly reduced. Lastly, it results in large open spaces inside the individual prints, so that when they are used as building components, these spaces could allow for the integration of other building components or systems. Therefore, robotic 3D spatial printing has been greatly anticipated in the field of architecture. This workshop specifically focused on exploring the feasibility of generating a complex morphological structure through a self-built PLA extruder. This required repetitiously optimizing the extruding system to reliably accommodate the various demands of spatial printing. The end-tool became the priority, as very precise temperature changes had profound impacts on the overall design of the structure.

If the temperature at the nozzle gets too high, the material will be overheated, producing bubbles that affect the appearance and structural strength of the work. If the temperature is too low, it will reduce the viscosity of the material and lead to insufficient joint strength. In addition, the wind speed of the cooling airflow and the extrusion rate of the material will have a direct impact on the printing results. These issues became the focus of the optimization as they had the most profound impact on the overall design, simulation, and material properties of the final product. As such, this workshop demonstrated that the third stage of the workflow (development of the end tool) is equally a critical part of the platform and greatly effects the efficiency of the entire system.

\subsection{Robotic Wood Assembly}

Wood was once one of the most widely used of the traditional building materials. However, after the introduction and spread of reinforced concrete and steel in the AEC industry, the frequency of wood has been greatly decreased. The main exceptions are in some earthquake-prone regions such as Japan and California due to concrete's poor resistance to disasters, high maintenance costs, and so on. Wood is relatively renewable and provides effective sound insulation, heat insulation, moisture resistance, earthquake resistance, and corrosion resistance, while wood-structure buildings benefit from fast construction speed, low initial cost, and high comfort. These advantages have drawn attention back to wood in recent years and have inspired further research and development on wooden structures [49].

With the development of wood treatment and processing technology, the performance of wood has been continuously improved to meet the needs of contemporary architectural functions. Now, with digital construction and rapid modular construction, wood can be freed from the limitations of traditional timber construction techniques. Formal complexity and accuracy, which are difficult to achieve by traditional techniques, can be realized efficiently with the introduction of robotics into the workflow. Computer-aided parametric modeling and logical production make it possible to use wood to form complex structures through the optimization of its properties [50]. Through force analysis and formal optimization of the structure, an assembly can achieve excellent structural performance while maintaining uniformity, minimizing material waste, and achieving excellent aesthetic values such as formal complexity, quality lighting, and natural textures. The wood structure can now break through its traditional formality and parlay into the world of rapid construction of modular materials.

In this workshop, to maximize formal and aesthetic quality, parametric computation was used to analyze the forces on the final structure, which allowed the team to explore the feasibility of complex assembly methods for wood construction. Here, the construction of the assembly became the driving factor for the other stages of the robotic tectonic framework. The pick and place method of assembly was selected as the primary construction method, which was subsequently simulated to eliminate any problems that may be encountered during the robotic construction. The large, free standing structure required an extremely stable foundation, so the team also carried out a number of similar schemes for the foundation. In doing so, they had to perform many lab tests for damage resistance before building the final structure in order to explore its feasibility (see Figure 5). The construction and the 
installation of the entire structure was completed in 3 days with 780 pieces of wood, 1388 glue joints, and 2852 tapping nails.

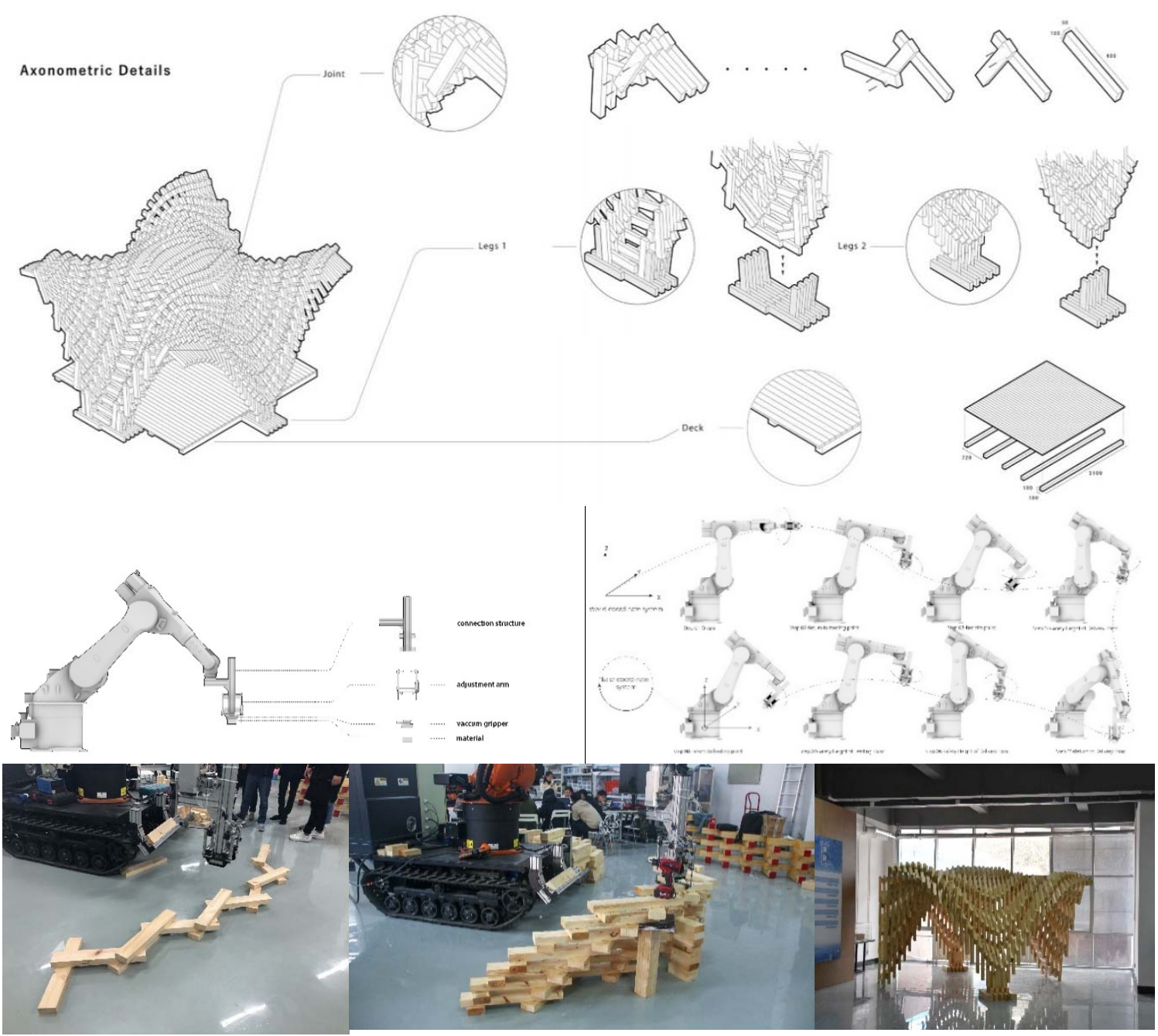

Figure 5. The robotic construction process for wood assembly structures.

\section{Discussion and Conclusions}

The four workshops mentioned above each prioritized one of the four stages of the pedagogical framework, while all of them followed the continuous workflow of the new didactic method. They provide examples of how each stage of the pedagogy is critical to understanding the whole system and how a better understanding of the system can lead to improved efficiency in automated construction. As a result, this proposed pedagogy is set to meet the new demands of sustainable architectural education in this digitally dominated era. The introduction of this workflow at the academic level is critical, as iteration and continuous study improve its accuracy and efficiency recursively. The more time students spend exploring each of the four stages, the more they will be able to design with the whole robotic tectonics process in mind, thus developing more optimized and sustainable designs. To recap:

1. Parametric design has already had a remarkable effect on sustainable architectural design. Its logical workflow could easily bring interdisciplinary techniques of design and construction together for testing, generating, and analysis in a digital environment. As the first component of the pedagogy, parametric design asks students to focus on the digital modeling of design concepts through the lens of parametric logic. In this stage, the logic-based digital architectural model is 
established and becomes a platform for the upcoming simulation, application, experimentation, and modification of the design. By benefiting the user in time-sensitive, dynamic design scenarios, parametric design could help students explore more design possibilities. Take "Robotic Clay Printing" as an example. Through parametric design, we guided students to experiment with the Voronoi algorithm in order to achieve a creative solution for building more efficient ventilation panels. Once printed and analyzed, it was clear that this experiment brought novel sustainability and critical thinking concepts into their design processes.

2. Cross-data simulation requires students to understand different types of data (such as fabrication constraints and tool-path data) and merge them into one virtual simulated environment, which provides a safe method for students or architects to analyze every detailed step of the construction process before its implementation. There is no doubt that doing so will significantly reduce the risk of production error, thereby saving material, labor, time, and cost. In the case of "Robotic Foam Cutting," the simulation revealed the process of cutting an infinite complex surface via its tool path. Through this robot-oriented simulation process, we are helping students to create new forms and spaces with minimum material use and almost zero waste in fabrication.

3. Robotic application acts as a critical component of the robotic construction process in that it is the main bridge between digital simulation and physical construction. Only with an end effector's exquisite design and efficient operation can the project achieve the precision necessary for more sustainable design. This stage helps students to realize how to deal with new materials, fabrication tools, operation constraints, mechanical and electronic design, and tool development. It is an interdisciplinary stage where the physicality of the final product must finally be considered. In the case of "Robotic 3D Spatial Printing," we helped students develop the PLA extruder end effector, which dealt with sensitive control of the printing temperature and coordination between the extruding speed and tool path. This experiment was able to improve the sustainability of the project through the fabrication of complex components without a support system, in less time, and with minimal material.

4. Robotic construction exemplifies how robotic tectonic practices might achieve our goal of architectural sustainability in the digital era. It represents the comprehensive stage for students to operate, test, build, collaborate, and ultimately achieve their initial design concept. Here, the students may also garner the most insight for new design concepts, as the constraints of the physical world are most obvious. For "Robotic Wood Assembly," precision, efficiency, material economy, and human-robot collaboration processes gave all the participants remarkable insight for the potential for sustainability through robotic tectonics and automated construction.

This novel pedagogical framework explores the complete architectural design and construction cycle. It represents a methodical approach to the "design-to-fabrication process" and provides students with the necessary technical skills required to make automated construction a reality. Furthermore, it creates a global platform on which students can explore and critically apply contemporary technology in order to push the limits of sustainability in both the profession and education. It aims to introduce the multi-faceted type of knowledge required to use robotics for automated construction, to demonstrate evidence of economic, social, and environmental improvements to the built world, and to provide insight into new and complex building processes that will redefine architecture in the near future.

Author Contributions: Conceptualization, X.S.; Data curation, X.S. and Z.C.; Funding acquisition, X.S. and X.F.; Investigation, X.S.; Methodology, X.S. and X.F.; Project administration, X.S.; Resources, X.F. and H.F.; Software, Z.C.; Supervision, X.F. and H.F.; Validation, T.K.P. and H.F.; Writing—original draft, X.S., X.F., and Z.C.; Writing一review and editing, X.F., Z.C., T.K.P., and H.F. All authors have read and agree to the published version of this manuscript.

Funding: This research was funded by the Key Technology Research and Development Program of Shandong (2019GSF110004, Research and Development of Simulation and Programming Technology for the Integration of Green Building Design and Robot Construction) and the Innovation Institute for Sustainable Maritime Architecture Research and Technology (iSMART) of Qingdao University of Technology. 
Acknowledgments: The authors would like to acknowledge and express their gratitude to all the tutors for workshops: Alexander Kalachev and Olga Kovrikava from UN-Studio, Tudor Cosmatu from TU-Delft, Chao Han from BIAD, Da Wan and Guanqi Zhu from Tianjin Chengjian University, Dawei $\mathrm{Xu}$ and Zhuoqun Jiang from Qingdao University of Technology, and all the participants who joined the "robotic tectonics" workshops hosted by DAMlab.

Conflicts of Interest: Authors declare no conflicts of interest. The funders had no role in the design of the study; in the collection, analyses, or interpretation of data; in the writing of the manuscript; or in the decision to publish the results.

\section{References}

1. Healey, P.; Shaw, T. Planners, plans and sustainable development. Reg. Stud. 1993, 27, 769-776. [CrossRef]

2. UN General Assembly. 2005 World Summit Outcome; UN General Assembly: New York, NY, USA, 2005.

3. Porritt, J. Capitalism as If the World Matters; Routledge: Abingdon-on-Thames, UK, 2005.

4. Capra, F.; Luisi, P.L. The Systems View of Life: A Unifying Vision; Cambridge University Press: Cambridge, UK, 2014.

5. Ayres, R.U.; Turton, H.; Casten, T. Energy efficiency, sustainability and economic growth. Energy 2007, 32, 634-648. [CrossRef]

6. Chang, J.; Leung, D.Y.C.; Wu, C.Z.; Yuan, Z.H. A review on the energy production, consumption, and prospect of renewable energy in China. Renew. Sustain. Energy Rev. 2003, 7, 453-468. [CrossRef]

7. Du Pisani, J.A. Sustainable development-Historical roots of the concept. Environ. Sci. 2006, 3, 83-96. [CrossRef]

8. Mokyr, J. Chapter 2-The contribution of economic history to the study of innovation and technical change: 1750-1914. In Handbook of the Economics of Innovation; Hall, B.H., Rosenberg, N., Eds.; North-Holland: Amsterdam, The Netherlands, 2010; Volume 1, pp. 11-50.

9. Gerbert, P.; Castagnino, S.; Rothballer, C.; Renz, A.; Filitz, R. Digital-in-Engineering-and-Construction; Boston Consulting Group: Boston, MA, USA, 2016; pp. 1-22.

10. Parliament, E. Directive 2010/31/EU of the European parliament and of the council of 19 May 2010 on the energy performance of buildings. Off. J. Eur. Union 2010, 18, 153.

11. U.S. Bureau of Labor Statistics. Construction Laborers and Helpers_Occupational Outlook Handbook; U.S. Bureau of Labor Statistics: Washington, DC, USA, 2019.

12. Chen, Q.; García de Soto, B.; Adey, B.T. Construction automation: Research areas, industry concerns and suggestions for advancement. Autom. Constr. 2018, 94, 22-38. [CrossRef]

13. García de Soto, B.; Agustí-Juan, I.; Hunhevicz, J.; Joss, S.; Graser, K.; Habert, G.; Adey, B.T. Productivity of digital fabrication in construction: Cost and time analysis of a robotically built wall. Autom. Constr. 2018, 92, 297-311. [CrossRef]

14. Yuan, P.F.; Leach, N.; Menges, A. Digital Fabrication; Tongji University Press Co., Ltd.: Shanghai, China, 2018.

15. Yuan, P.F.; Meng, H.; Devadass, P. Performative tectonics. In Robotic Fabrication in Architecture, Art and Design 2014; McGee, W., Ponce de Leon, M., Eds.; Springer International Publishing: Cham, Switzerland, 2014; pp. 181-195. [CrossRef]

16. Austern, G.; Capeluto, I.G.; Grobman, Y.J. Rationalization methods in computer aided fabrication: A critical review. Autom. Constr. 2018, 90, 281-293. [CrossRef]

17. Leach, N.; Yuan, P.F. Computational Design; Tongji University Press Company Limited: Shanghai, China, 2018.

18. Leach, N.; Xu, W.G. Emerging Talents, Emerging Technologies; China Architecture \& Building Press: Beijing, China, 2006; pp. 6-15.

19. Yuan, P. Parametric regionalism. Archit. Des. 2016, 86, 92-99. [CrossRef]

20. Gramazio, F.; Kohler, M. Digital Materiality in Architecture; Lars Müller Publishers: Baden, Switzerland, 2008.

21. Mavromatidis, L. Constructal macroscale thermodynamic model of spherical urban greenhouse form with double thermal envelope within heat currents. Sustainability 2019, 11, 3897. [CrossRef]

22. Mavromatidis, L. Linking wide-ranging geometrical and non-geometrical glazing options for daylight effectiveness estimation at an early design stage. Energy Procedia 2015, 78, 711-716. [CrossRef]

23. Mavromatidis, L. Coupling architectural synthesis to applied thermal engineering, constructal thermodynamics and fractal analysis: An original pedagogic method to incorporate "sustainability" into architectural education during the initial conceptual stages. Sustain. Cities Soc. 2018, 39, 689-707. [CrossRef] 
24. Bejan, A. Sustainability: The water and energy problem, and the natural design solution. Eur. Rev. 2015, 23, 481-488. [CrossRef]

25. Bock, T. The future of construction automation: Technological disruption and the upcoming ubiquity of robotics. Autom. Constr. 2015, 59, 113-121. [CrossRef]

26. Bock, T.; Linner, T. Construction Robots-Elementary Technologies and Single-Task Construction Robots; Cambridge University Press: Cambridge, UK, 2017. [CrossRef]

27. Gramazio, F.; Kohler, M.; Willmann, J. The Robotic Touch. How Robots Change Architecture: Gramazio E Kohler Research ETH Zurich 2005-2013; Park Books: Zürich, Switzerland, 2014.

28. Mateus, R.; Bragança, L. Sustainability assessment and rating of buildings: Developing the methodology SBToolPT-H. Build. Environ. 2011, 46, 1962-1971. [CrossRef]

29. Ursprung, P. Matter and Memory: Archi-Union's Surfaces; Yuan, P.F., Ed.; Oscar Riera Ojeda Publishers: Shenzhen, China, 2018; p. 219.

30. Picon, A. Futurism and nostalgia aside: Digital design and fabrication according to Archi-Union", préface à Philip F. Yuan. In Collaborative laboratory Works of Archi-Union and Fab-Union; Oscar Riera Publishers: Hong Kong, China, 2018; pp. 12-17.

31. Bock, T.; Linner, T. Robotic Industrialization: Automation and Robotic Technologies for Customized Component, Module, and Building Prefabrication; Cambridge University Press: Cambridge, UK, 2015; pp. 1-238. [CrossRef]

32. Yablonina, A.; Prado, M.; Baharlou, M.; Schwinn, E.; Menges, T. Fabricate rethinking design and construction. In Proceedings of the Fabricate Conference, Stuttgart, Germany, 2017; pp. 202-209.

33. Leach, N. Digital morphogenesis. Archit. Des. 2009, 79, 32-37. [CrossRef]

34. Bechthold, M. The return of the future: A second go at robotic construction. Archit. Des. 2010, 80, $116-121$. [CrossRef]

35. Wei-Guo, X. Parametric Non-linear Architecture Design; Tsinghua University: Beijing, China, 2016; pp. $190-191$.

36. Wei-Guo, X. Ditigal Architecture Design Works; Tsinghua University: Beijing, China, 2016.

37. Karsl1, U.T.; Özker, S. The contributions of workshops on formal interior architecture education. Procedia Soc. Behav. Sci. 2014, 152, 47-52. [CrossRef]

38. Fien, J.; Tilbury, D. The global challenge of sustainability. Educ. Sustain. Respond. Glob. Chall. 2002, 1, 204.

39. Porras Álvarez, S.; Lee, K.; Park, J.; Rieh, S.Y. A comparative study on sustainability in architectural education in Asia-With a focus on professional degree curricula. Sustainability 2016, 8, 290. [CrossRef]

40. Rahman, A. Greening the architectural curriculum in all the malaysian institutes of higher learning-It is not an option. Archnet Int. J. Archit. Res. 2010, 4. [CrossRef]

41. Altomonte, S. Sustainable Architectural Education-White Paper; EDUCATE Press: Nottingham, UK, $2012 ;$ p. 38.

42. Hensel, M.; Menges, A.; Weinstock, M. Emergence: Morphogenetic Design Strategies; Wiley-Academy: Chichester, UK, 2004.

43. Stumm, S.; Braumann, J.; von Hilchen, M.; Brell-Cokcan, S. On-site robotic construction assistance for assembly using a-priori knowledge and human-robot collaboration. In Proceedings of the Advances in Robot Design and Intelligent Control, Belgrade, Serbia, 30 June-2 July 2016; pp. 583-592.

44. Keating, S.; Oxman, N. Compound fabrication: A multi-functional robotic platform for digital design and fabrication. Robot. Comput. Integr. Manuf. 2013, 29, 439-448. [CrossRef]

45. Friedman, J.; Kim, H.; Mesa, O. Experiments in additive clay depositions. In Robotic Fabrication in Architecture, Art and Design 2014; McGee, W., Ponce de Leon, M., Eds.; Springer International Publishing: Cham, Switzerland, 2014; pp. 261-272. [CrossRef]

46. Melnikova, R.; Ehrmann, A.; Finsterbusch, K. 3D printing of textile-based structures by Fused Deposition Modelling (FDM) with different polymer materials. In Proceedings of the IOP Conference Series: Materials Science and Engineering, Ningbo, China, 27-29 May 2014; p. 012018.

47. Yuan, P.F.; Meng, H.; Yu, L.; Zhang, L. Robotic Multi-dimensional Printing Based on Structural Performance. In Robotic Fabrication in Architecture, Art and Design 2016; Reinhardt, D., Saunders, R., Burry, J., Eds.; Springer International Publishing: Cham, Switzerland, 2016; pp. 92-105. [CrossRef]

48. Gaub, H. Customization of mass-produced parts by combining injection molding and additive manufacturing with Industry 4.0 technologies. Reinf. Plast. 2016, 60, 401-404. [CrossRef] 
49. Menges, A.; Schwinn, T.; Krieg, O.D. Advancing Wood Architecture: A Computational Approach; Routledge: Abingdon, UK, 2016.

50. Willmann, J.; Knauss, M.; Bonwetsch, T.; Apolinarska, A.A.; Gramazio, F.; Kohler, M. Robotic timber construction-Expanding additive fabrication to new dimensions. Autom. Constr. 2016, 61, 16-23. [CrossRef] 